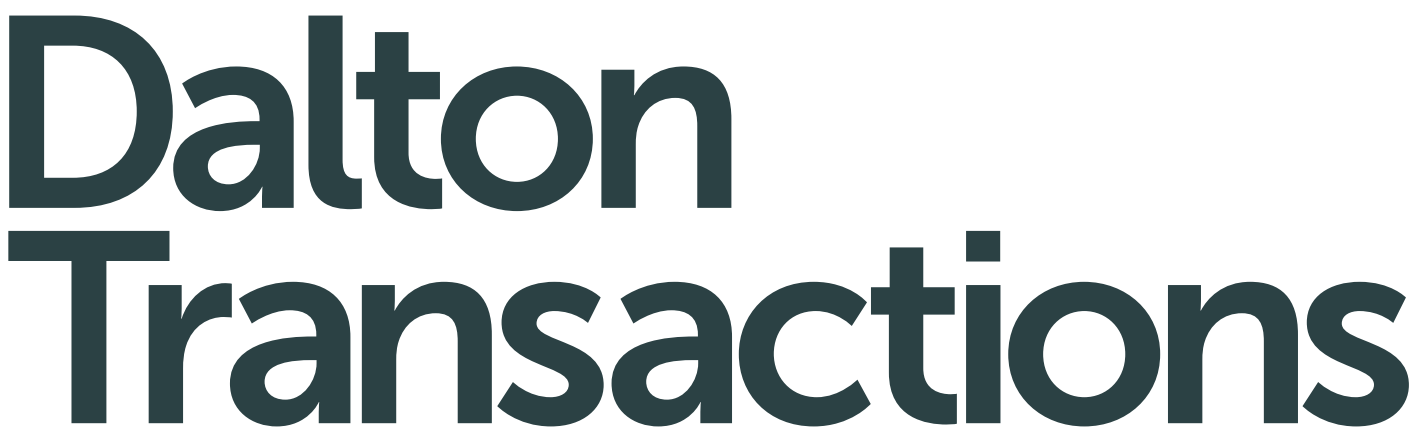

An international journal of inorganic chemistry rsc.li/dalton

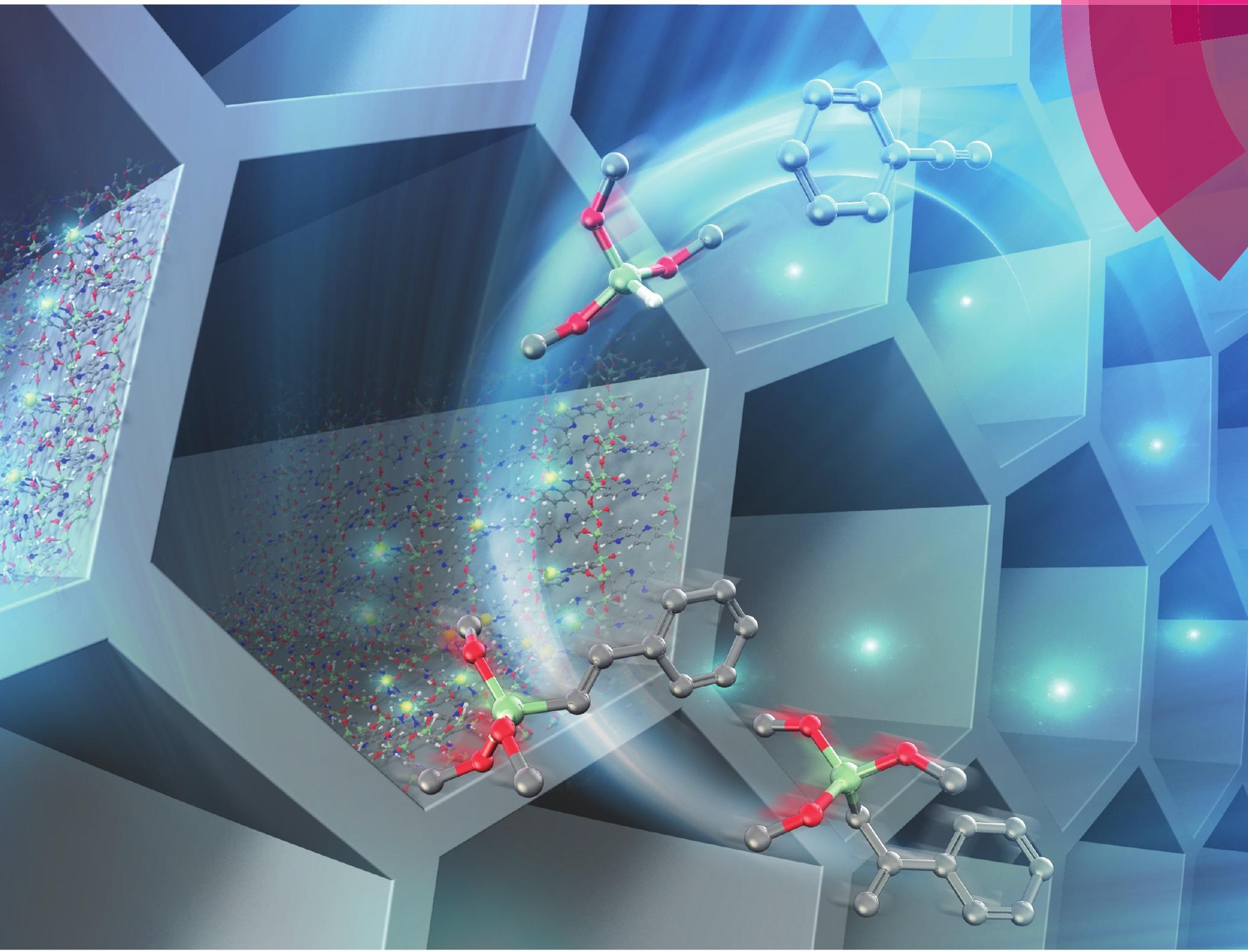

ISSN 1477-9226 


\section{D) Check for updates}

Cite this: Dalton Trans., 2019, 48 5534

Received 7th January 2019, Accepted 7th February 2019

DOI: 10.1039/c9dt00078j

rsc.li/dalton

\title{
Heterogeneous hydrosilylation reaction catalysed by platinum complexes immobilized on bipyridine- periodic mesoporous organosilicas $\uparrow$
}

\author{
Yuki Naganawa, (D) a Yoshifumi Maegawa, (DD b Haiqing Guo, ${ }^{a}$ \\ Sandeep Suryabhan Gholap, ${ }^{a}$ Shinji Tanaka, (D) a Kazuhiko Sato, ${ }^{a}$ Shinji Inagaki (D) *a,b \\ and Yumiko Nakajima (D) *a
}

\begin{abstract}
The utility of a bipyridine periodic mesoporous organosilica, BPy-PMO, as a support material of a hydrosilylation catalyst was investigated in the hydrosilylation of phenylacetylene with trimethoxysilane. [PtMe $\left.\mathrm{P}_{2}(\mathrm{BPy}-\mathrm{PMO})\right]$ (1) exhibited a moderate catalytic activity, whereas the reaction was successfully catalysed by $\left[\mathrm{PtMe}_{2}(\mathrm{BPy}-\mathrm{PMO}-\mathrm{TMS})\right]$ (2) bearing end-capped TMS groups on the surface. Spectroscopic analyses of $\mathbf{2}$ revealed that the porous structure of BPy-PMO-TMS remained almost unchanged through the reaction. The hot filtration test supported the nonleaching property of $\mathbf{2}$, thereby exhibiting good reusability without the loss of the product yields.
\end{abstract}

\section{Introduction}

Hydrosilylation is one of the most important methods for the synthesis of various organosilicon compounds. ${ }^{1}$ Platinum catalysts, such as Speier's catalyst $\left(\mathrm{H}_{2} \mathrm{PtCl}_{6}\right)^{2}$ and Karstedt's catalyst, ${ }^{3}$ are widely utilized in the silicon industry because they exhibit high catalytic activity, selectivity, and high stability toward oxygen and moisture. As a result, significant amounts of Pt are consumed in the silicon industry (5.6 tons in 2007, ca. $3 \%$ of the annual global platinum production), ${ }^{4}$ and the high cost and uncertainty of the long-term supply of precious platinum are becoming a larger issue. In addition, separating the catalyst from the reaction mixture is often problematic in some industrial processes. ${ }^{1 c}$ As a result, the development of a hydrosilylation process using immobilized Pt catalysts, which has the advantage of easy catalyst recovery, is attracting great interest. $^{5}$

To prepare immobilized hydrosilylation catalysts, a wide variety of support materials have been used to date, including both organic polymers and inorganic substrates. ${ }^{6}$ The substrates normally possess functional linkages and connect with active metal centers, which sometimes interact with neighboring metals due to the flexible nature of the linkers, leading to

\footnotetext{
${ }^{a}$ Interdisciplinary Research Center for Catalytic Chemistry, National Institute of Advanced Industrial Science and Technology, Tsukuba, Ibaraki 305-8565, Japan. E-mail: yumiko-nakajima@aist.go.jp

${ }^{b}$ Toyota Central R\&D Laboratories, Inc., Nagakute, Aichi 480-1192, Japan.

E-mail: inagaki@mosk.tytlabs.co.jp

$\dagger$ Electronic supplementary information (ESI) available. See DOI: 10.1039/ c9dt00078j
}

a decrease in their catalytic performances. An alternative way to develop novel heterogeneous catalysts from effective homogeneous catalysts is to support them directly on high-surfacearea solids without a linker. ${ }^{7}$ In this context, we focus on a periodic mesoporous organosilica containing a 2,2'-bipyridine (bpy) unit within the framework (bipyridine-periodic mesoporous organosilica: BPy-PMO) $)^{8-16}$ as a solid chelating ligand (Fig. 1). In the structure of BPy-PMO, the 2,2'-bipyridine ligands are regularly and densely arranged in the siloxane network and exposed on the pore surface with a large specific surface area $\left(>600 \mathrm{~m}^{2} \mathrm{~g}^{-1}\right)$. Thus, BPy-PMO enables us to directly immobilize various homogeneous catalysts on the molecularly well-defined pore surface and thus suppress undesired interaction and aggregation of the metal centers. Another notable feature of BPy-PMO is the large pore size $(3.8 \mathrm{~nm}$ in diameter), which allows the smooth diffusion of reactant molecules in the mesochannel. By utilizing these characteristic pro-

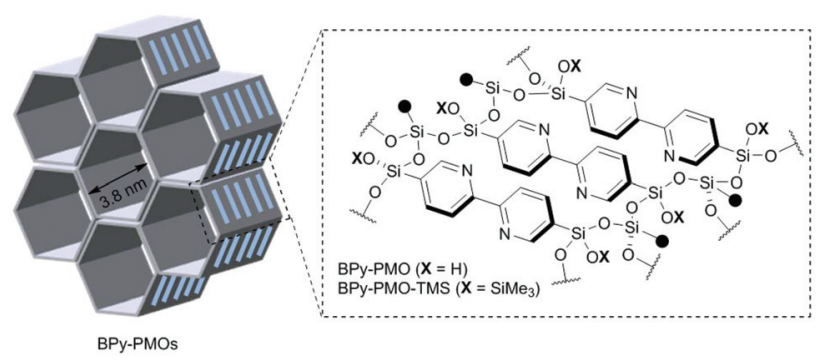

Fig. 1 Bipyridine-periodic mesoporous organosilica (BPy-PMO, $X=H$ ) and end-capped BPy-PMO (BPy-PMO-TMS, X = SiMe 3 ). 
perties, we have thus far synthesized various BPy-PMO-based metal complexes including $\mathrm{Ir}^{8-10} \mathrm{Ru},{ }^{8,11,12} \mathrm{Re},{ }^{8,13} \mathrm{Pd},{ }^{8} \mathrm{Au},{ }^{14}$ $\mathrm{Mo},{ }^{15}$ and $\mathrm{Rh}^{16}$ on the PMO pore surface and demonstrated their utility as heterogeneous catalysts for organic syntheses. . $^{8,9,13,14-16}$

Herein, we synthesized BPy-PMO-based Pt complexes ${ }^{17}$ as hydrosilylation catalysts. A carrier support of hydrosilylation catalysts should be thermally and chemically stable during the reaction and must provide good accessibility and dispersion of the active sites to apply the catalyst system for the curing of silicone products. Considering this, we were motivated to examine the utility of BPy-PMO as the support of the hydrosilylation catalyst. In this study, we tested two types of BPyPMO bearing different siloxane frameworks with silanol groups ( $\mathbf{X}=\mathrm{H}$; BPy-PMO) or TMS-protected silanol groups $(\mathbf{X}=$ $\mathrm{SiMe}_{3} ; \mathrm{BPy}-\mathrm{PMO}-\mathrm{TMS}$ ) as shown in Fig. 1.

\section{Results and discussion}

\section{Formation of Pt complexes on solid supports}

First, the formation of bipyridine-based Pt complex ${ }^{17}$ was attempted by simply mixing BPy-PMO and Karstedt's catalyst as a precursor complex in solution. However, the reaction was not successful, leading to the formation of the compounds with a small Pt loading amount of $\sim 30 \mu \mathrm{mol} \mathrm{g}^{-1}$. This result indicates that BPy-PMO is not a suitable support for the Karstedt's catalyst. Formation of Pt(II) complex was then performed by following the synthetic procedure of $\left.\left[\mathrm{PtMe}_{2}(\mathrm{bpy})\right]\right]^{18}$ in which $\left[\mathrm{PtMe}_{2}\left(\mu-\mathrm{SMe}_{2}\right)\right]_{2}$ was used as a precursor. Rigorous stirring of the powder of BPy-PMOs ( $\mathbf{X}=\mathrm{H}$ and $\mathrm{SiMe}_{3}$; Fig. 1) in a benzene solution containing $\left[\mathrm{PtMe}_{2}\left(\mu-\mathrm{SMe}_{2}\right)\right]_{2}(0.15$ equiv. of bpy unit on surface) at $6{ }^{\circ} \mathrm{C}$ resulted in the formation of $\left[\mathrm{PtMe}_{2}(\mathrm{BPy}-\mathrm{PMO})\right]$ (1) (Scheme 1; see the ESI $\dagger$ ). The white color
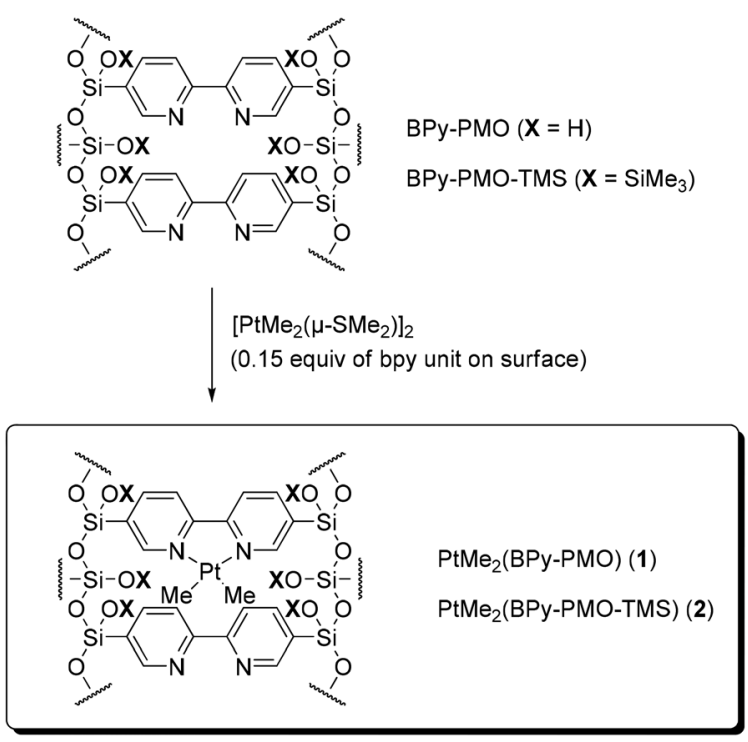

Scheme 1 Synthesis of $\left[\mathrm{PtMe}_{2}(\mathrm{BPy}-\mathrm{PMO})\right]$ (1) and $\left[\mathrm{PtMe}_{2}(\mathrm{BPy}-\right.$ PMO-TMS)] (2). of BPy-PMO changed to light pink (1) or purple (2), implying the formation of Pt-bipyridine complex on the pore surface of BPy-PMO. Graft-type Pt-bipyridine complexes $\mathbf{3 a}$ and $\mathbf{3 b}$ were also prepared for comparison using TMS-protected mesoporous silica (FSM-16) and silica gel as a support, respectively (Scheme 2; Fig. S1 and S2†).

\section{Characterization of Pt-complex-immobilized solid supports}

The amounts of bipyridine ligand in solid supports and Pt in catalysts 1, 2, 3a, and 3b were measured by CHN elemental analysis and energy-dispersive X-ray spectrometry (EDX) analysis, respectively. The results are summarized in Table 1. The amounts of bipyridine ligand in BPy-PMO and BPy-PMO-TMS were 3.18 and $2.92 \mathrm{mmol} \mathrm{g}^{-1}$. Pt loading amounts in $\mathbf{1}$ and 2 were 0.26 and $0.36 \mathrm{mmol} \mathrm{g}^{-1}$. When all Pt ions coordinated with bipyridine ligands in 1:1 ratio, this EDX result indicates that there are large amounts of free bipyridine units $(88 \%$ for 1 and $82 \%$ for 2) on the pore surface (see, Experimental section). In contrast, although the loading amounts of Pt in $\mathbf{3 a}$ and $\mathbf{3 b}$ were similar to those of bipyridine ligands in the supports $\left(0.38 \mathrm{mmol} \mathrm{g}^{-1}\right.$ for $3 \mathbf{a}$ and $0.36 \mathrm{mmol} \mathrm{g}^{-1}$ for $\left.3 \mathbf{b}\right)$, almost no free bipyridine ligands exist in $\mathbf{3 a}$ and $\mathbf{3 b}$.

To investigate the structural change of solid supports during the immobilization of Pt complex, powder X-ray diffraction (XRD) patterns and nitrogen adsorption/desorption isotherms were measured (Fig. S3-S6†). The XRD patterns of 1, 2, and 3a showed an intense peak at $2 \theta$ values of $1.86^{\circ}, 1.82^{\circ}$, and $1.88^{\circ}$, respectively, indicating that well-ordered mesostructures of parent solid supports remained (Fig. S3-S5†). For PMO complexes 1 and 2, four additional peaks were observed at scattering angles of $7.60^{\circ}, 15.2^{\circ}, 22.9^{\circ}$, and $30.8^{\circ}$ due to the molecular-scale periodicity of the bipyridine groups in the pore walls (Fig. S3 and S4 $\dagger$ ). Table 1 summarizes the values of the Brunauer-Emmett-Teller surface area $\left(S_{\mathrm{BET}}\right)$ and $t$-plot pore volume $\left(V_{t \text {-plot }}\right)$, and the density functional theory pore diameter $\left(d_{\mathrm{DFT}}\right)$ obtained from nitrogen adsorption/desorption isotherms of four solid catalysts and parent solid supports (Fig. S7 and S8 $\dagger$ ). For 1, $S_{\mathrm{BET}}, V_{t \text {-plot, }}$ and $d_{\mathrm{DFT}}$ values were decreased compared with those of parent BPy-PMO, indicating

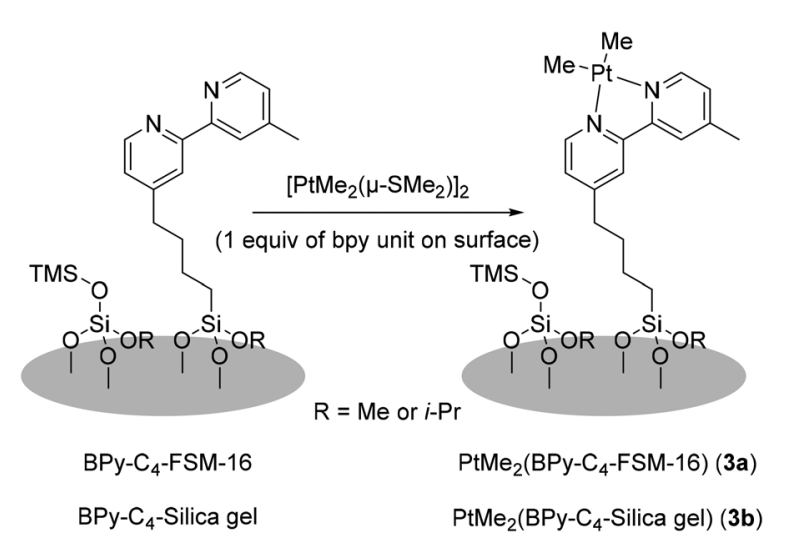

Scheme 2 Synthesis of $\left[\mathrm{PtMe}_{2}\left(\mathrm{BPy}-\mathrm{C}_{4}-\mathrm{FSM}-16\right)\right]$ (3a) and [PtMe 2 (BPy$\mathrm{C}_{4}$-Silica gel)] (3b). 
Table 1 Physicochemical properties of PMO complexes 1 and 2, and graft-type complexes 3a and 3b

\begin{tabular}{|c|c|c|c|c|c|}
\hline Sample & bpy unit ${ }^{a}\left[\mathrm{mmol} \mathrm{bpy} \mathrm{g}{ }^{-1}\right]$ & Pt amount ${ }^{b}\left[\mathrm{mmol} \mathrm{Pt} \mathrm{g}^{-1}\right]$ & $S_{\mathrm{BET}}^{c}\left[\mathrm{~m}^{2} \mathrm{~g}^{-1}\right]$ & $V_{t \text {-plot }}{ }^{c}\left[\mathrm{~cm}^{3} \mathrm{~g}^{-1}\right]$ & $d_{\mathrm{DFT}}^{c}[\mathrm{~nm}]$ \\
\hline 1 & - & 0.26 & 478 & 0.31 & 3.9 \\
\hline BPy-C ${ }_{4}-\mathrm{FSM}-16$ & 0.38 & - & 575 & 0.44 & 3.8 \\
\hline $3 a$ & - & 0.38 & 528 & 0.36 & 3.8 \\
\hline BPy-C ${ }_{4}$-Silica gel & 0.42 & - & 402 & 0.46 & 5.7 \\
\hline
\end{tabular}

${ }^{a}$ The amounts of bpy unit in support were determined by CHN elemental analysis. ${ }^{b}$ Determined by EDX analysis. ${ }^{c}$ Determined from nitrogen adsorption/desorption isotherms at liquid nitrogen temperature and calculated using the BET method $\left(S_{\mathrm{BET}}\right)$, $t$-plot method $\left(V_{t \text {-plot }}\right)$, or density functional theory $\left(d_{\mathrm{DFT}}\right)$.

the occurrence of partial structural change by immobilization of the Pt complex. In contrast, $S_{\mathrm{BET}}, V_{t \text {-plot }}, d_{\mathrm{DFT}}$ values of 2 and BPy-PMO-TMS were nearly constant, meaning the preservation of uniform mesoporous structure even after the immobilization of the Pt complex. This result is ascribed to improvement in the structural stability of the pore framework by TMS protection. A similar positive effect by the TMS group was also previously reported for BPy-PMO. ${ }^{15}$ For $3 \mathbf{a}$ and $\mathbf{3 b}, S_{\mathrm{BET}}, V_{t \text {-plot }}$, and $d_{\mathrm{DFT}}$ values were slightly reduced compared with those of parent supports, suggesting the almost complete preservation of original porous structures by TMS protection.

Complexation of Pt and bipyridine was confirmed by UV-vis diffuse reflectance spectroscopy (Fig. S9†). The UV-vis absorption spectrum of the model complex $\left[\mathrm{PtMe}_{2}(\mathrm{bpy})\right]$ in toluene showed partly structured absorption in the range of 400-600 nm due to the metal-to-ligand charge transfer (MLCT) band of the Pt-bipyridine complex. ${ }^{19}$ However, complex 1 showed a weak absorption in the same range. Because the absorption intensity is weak, a small amount of the desired Ptbipyridine complex seems to form on the pore surface. It is also likely that an undesired Pt complex was formed by the reaction of the Pt precursor with the surface silanol groups. In contrast, 2 showed a broad absorption band centered at $540 \mathrm{~nm}$ in the range of $450-650 \mathrm{~nm}$, which can be attributed to the Pt-bipyridine complex on the pore surface. The red-shift of the absorption band compared with that of $\left[\mathrm{PtMe}_{2}(\mathrm{bpy})\right]$ might be due to the changes in electronic state of the Pt-bipyridine complex by direct attachment of silicon atoms at both sides of the bipyridine ligand and end-capping of surface silanol groups with TMS groups. The red-shift of the MLCT band due to the silicon substitution was also reported in other metal-immobilized BPy-PMO. ${ }^{8}$ Graft-type complexes $\mathbf{3 a}$ and $\mathbf{3 b}$ showed a broad absorption band centered at $\sim 470 \mathrm{~nm}$, which is similar to that of $\mathrm{PtMe}_{2}$ (bpy) in toluene solution, indicating that $\mathbf{P t}$ complexes in $\mathbf{3} \mathbf{a}$ and $\mathbf{3 b}$ were located in a hydrophobic environment.

\section{Catalytic activity of Pt catalysts immobilized on BPy-PMO}

The catalytic activity of $\mathbf{1}$ and $\mathbf{2}$ toward hydrosilylation was examined using phenylacetylene as a model substrate (Table 2). Pt-catalysed hydrosilylation of terminal alkynes has
Table 2 Hydrosilylation of phenylacetylene ${ }^{a}$

\begin{tabular}{|c|c|c|c|c|c|}
\hline \multicolumn{2}{|c|}{$\begin{array}{c}\mathrm{Ph}=-\mathrm{H} \\
+ \\
(\mathrm{MeO})_{3} \mathrm{SiH}\end{array}$} & $\begin{array}{c}\text { Cat (5 mol\% Pt) } \\
\text { benzene } \\
60^{\circ} \mathrm{C} \text {, Time }\end{array}$ & \multicolumn{2}{|c|}{$\underbrace{\mathrm{Ph}}_{\substack{\mathrm{Si}(\mathrm{OMe})_{3} \\
\beta \text {-trans }}}$} & D) ${ }_{3} \mathrm{Si}^{\prime}$ \\
\hline Entry & \multicolumn{2}{|c|}{ Cat (time) } & $\begin{array}{l}\% \text { Conv. } \\
\text { alkyne }\end{array}$ & $\begin{array}{l}\% \text { Conv. } \\
\text { hydrosilane }\end{array}$ & $\begin{array}{l}\% \text { Yield }^{b} \\
{[\beta \text {-trans } / \alpha]}\end{array}$ \\
\hline 1 & \multicolumn{2}{|c|}{$1(15 \mathrm{~h})$} & 80 & 65 & $10[70 / 30]$ \\
\hline 2 & \multicolumn{2}{|c|}{$2(15 \mathrm{~h})$} & 85 & 82 & $78[72 / 28]$ \\
\hline 3 & \multicolumn{2}{|c|}{$2(24 \mathrm{~h})$} & $>99$ & $>99$ & $98[72 / 28]$ \\
\hline 4 & \multicolumn{2}{|c|}{$\left[\mathrm{PtMe}_{2}(\mathrm{bpy})\right](24 \mathrm{~h})$} & $>99$ & $>99$ & $97[72 / 28]$ \\
\hline 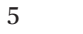 & \multicolumn{2}{|c|}{$3 \mathbf{a}(24 \mathrm{~h})$} & 97 & $>99$ & $97[72 / 28]$ \\
\hline 6 & \multicolumn{2}{|c|}{$3 \mathbf{b}(24 \mathrm{~h})$} & 93 & 97 & $93[71 / 29]$ \\
\hline
\end{tabular}

${ }^{a}$ Reaction conditions: Catalyst $(0.01 \mathrm{mmol} \mathrm{Pt})$, alkyne $(0.2 \mathrm{mmol})$, hydrosilane $(0.2 \mathrm{mmol})$ in benzene $(1 \mathrm{~mL})$ at $60{ }^{\circ} \mathrm{C} .{ }^{b}$ Determined by ${ }^{1} \mathrm{H}$ NMR analysis with mesitylene $(0.2 \mathrm{mmol})$ as an internal standard.

been extensively examined as one of the common preparation methods of a series of vinylsilanes, which are valuable synthetic intermediates in organic chemistry, although the mixture of $\beta$-trans and $\alpha$ adducts was often obtained in the reactions. ${ }^{20}$ In the presence of a catalytic amount of $\mathbf{1}(5 \mathrm{~mol} \%$ $\mathrm{Pt}$ ), the reaction of phenylacetylene with trimethoxysilane proceeded at $60{ }^{\circ} \mathrm{C}$, and the hydrosilylated product was obtained after $15 \mathrm{~h}$ as the mixture of $\beta$-trans and $\alpha$ adducts $(\beta$-trans $/ \alpha=$ $70 / 30)$, albeit in a low yield (10\%) (Table 2, entry 1). Complex 2 also catalysed the hydrosilylation reaction to give the hydrosilylated products in higher yield, $78 \%$, with the similar ratio of $\beta$-trans $/ \alpha=72 / 28$ (Table 2, entry 2). The yield was improved to $98 \%$ after a longer reaction time of $24 \mathrm{~h}$ (Table 2, entry 3).

A catalytic activity of a homogeneous catalyst, $\left[\mathrm{PtMe}_{2}(\mathrm{bpy})\right]$, was also tested for reference. This reaction afforded the hydrosilylated product in $97 \%$ yield with the $\beta$-trans $/ \alpha$ ratio of $72 / 28$ (Table 2, entry 4). Thus, no deleterious effect on the catalytic activity was observed after the immobilization on BPy-PMO.

It is noteworthy that both phenylacetylene and trimethoxysilane were considerably consumed, with $80 \%$ and $65 \%$ conversion, respectively, in the reaction catalysed by 1 , although the reaction gave only $10 \%$ yield of the products. We tentatively ascribe this lower product yield to the reactive silanol groups on the PMO-siloxane surface, which could react with hydrosilylated 


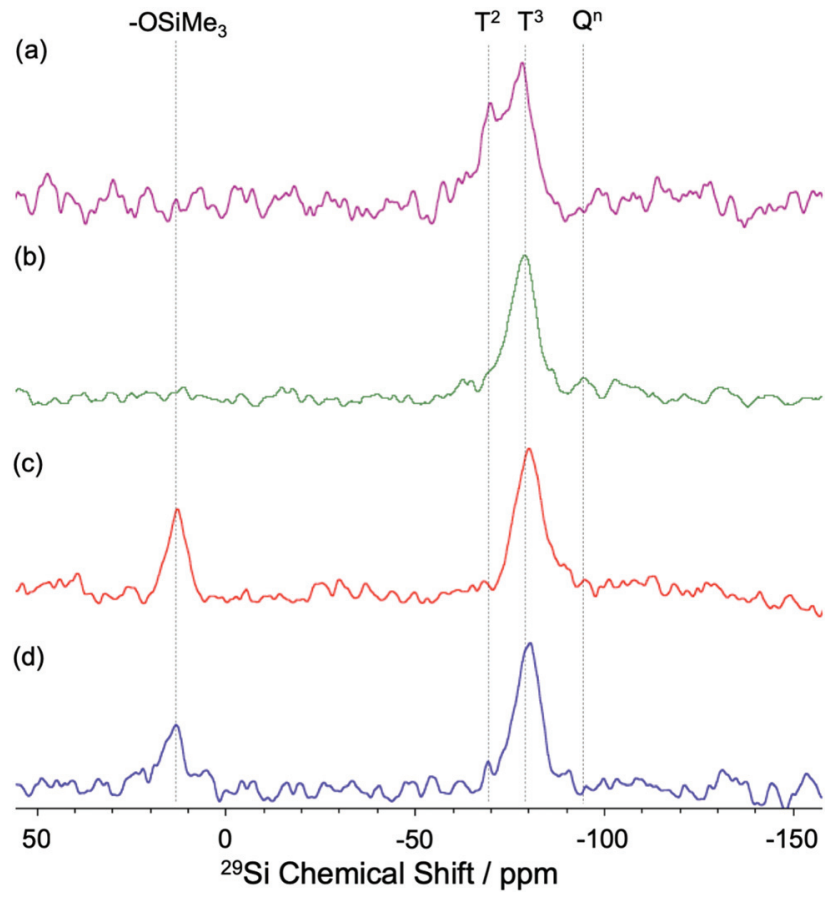

Fig. $2{ }^{29} \mathrm{Si}$ MAS NMR analyses of (a) 1, (b) 1 after hydrosilylation, (c) 2, and (d) 2 after hydrosilylation.

product, (trimethoxysilyl)styrene, to give the end-capped BPy$\mathrm{PMO}^{21}$ To elucidate this point, the solid-state ${ }^{29} \mathrm{Si}$ MAS NMR analysis was conducted. The ${ }^{29} \mathrm{Si}$ MAS NMR spectrum of 1 displayed two signals at $66.9 \mathrm{ppm}$ and $78.3 \mathrm{ppm}$ assignable to the $\mathrm{T}^{2}$ unit and $\mathrm{T}^{3}$ unit of siloxane matrix, respectively (Fig. 2(a)). The clear disappearance of the $\mathrm{T}^{2}$ unit of $\mathbf{1}$ after the catalytic reaction suggests the occurrence of a silane-coupling reaction between BPy-PMO and product, which leads to the conversion of the $\mathrm{T}^{2}$ unit to the corresponding $\mathrm{T}^{3}$ unit (Fig. 2(b)). Because the signal intensity of the $\mathrm{Q}^{n}$ unit was not sufficiently high to be identified under this measurement conditions, it is likely that the dehydrogenative coupling of silanol with trimethoxysilane hardly proceeded. The spectrum of 2 shows an additional signal due to the TMS protecting group at $12.9 \mathrm{ppm}$ instead of the $\mathrm{T}^{2}$ unit, indicating that the $\mathrm{T}^{2}$ unit in $\mathbf{1}$ was mostly consumed by TMS protection (Fig. 2(c)). As expected, there was no significant difference in ${ }^{29} \mathrm{Si}$ NMR spectrum after the hydrosilylation by 2 . Thus, the utility of TMS-end-capping to enhance chemical stability of the mesoporous structure was supported (Fig. 2(d)).

Complexes $\mathbf{3 a}$ and $\mathbf{3} \mathbf{b}$ exhibited similar catalytic activity to 2. Thus, under similar reaction conditions, the hydrosilylated products were obtained quantitatively with the $\beta$-trans/ $\alpha$ ratio of $72 / 28$ and $71 / 29$, respectively (Table 2 , entries 5 and 6 ). In contrast, hot filtration experiments showed significant differences in the leaching behavior of $\mathbf{2}, \mathbf{3 a}$, and $\mathbf{3} \mathbf{b}$. The reactions catalysed by $2,3 \mathbf{a}$, and $3 \mathbf{b}$ were conducted at $60^{\circ} \mathrm{C}$ at the catalyst loading of $5 \mathrm{~mol} \%$ Pt for 2 and $0.1 \mathrm{~mol} \%$ Pt for $\mathbf{3 a}$ and $\mathbf{3 b}$ and monitored by ${ }^{1} \mathrm{H}$ NMR spectroscopy. After stirring for $1 \mathrm{~h}$, filtration of the reaction mixture was performed at $60{ }^{\circ} \mathrm{C}$ and

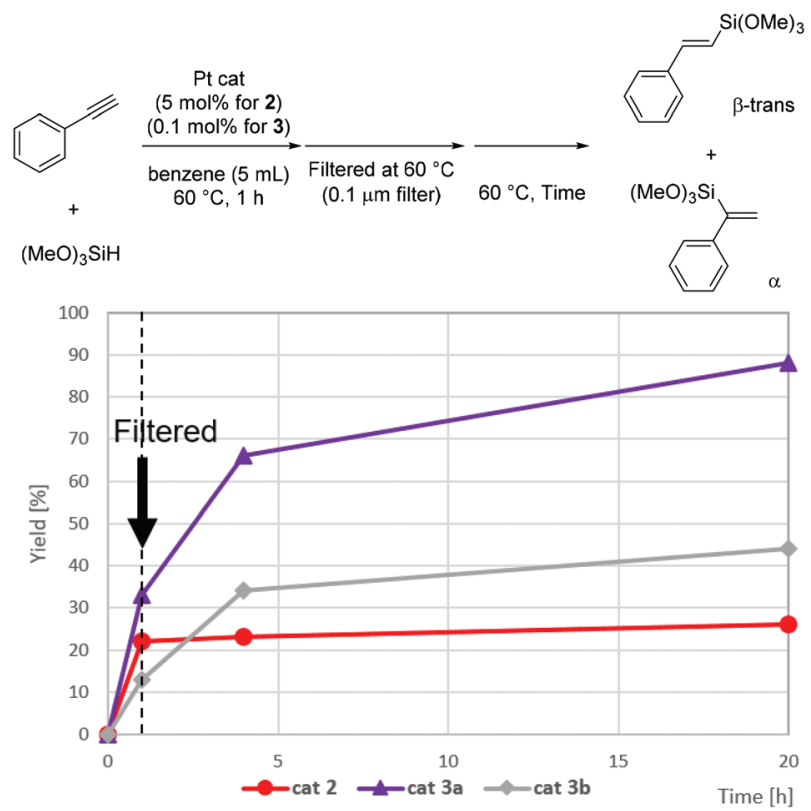

Fig. 3 Time course in the hot filtration test of hydrosilyllation of phenylacetylene and trimethoxysilane with cat 2 and 3. Reaction conditions: Catalyst $(0.01 \mathrm{mmol} \mathrm{Pt}$ for $2,0.001 \mathrm{mmol} \mathrm{Pt}$ for 3$)$, alkyne $(0.2 \mathrm{mmol}$ for $2,1.0 \mathrm{mmol}$ for 3$)$, hydrosilane $(0.2 \mathrm{mmol}$ for $2,1.0 \mathrm{mmol}$ for 3) in benzene ( $1 \mathrm{~mL}$ for $2,5 \mathrm{~mL}$ for 3) at $60{ }^{\circ} \mathrm{C}$. Determined by ${ }^{1} \mathrm{H}$ NMR analysis with mesitylene $(0.2 \mathrm{mmol}$ for $2,1.0 \mathrm{mmol}$ for 3$)$ as an internal standard.

the filtrate was further stirred at this temperature. The results are summarized in Fig. 3 . In the reaction catalysed by 2 , the yield of the hydrosilylated products was $22 \%$ after $1 \mathrm{~h}$ and this value remained unchanged for $20 \mathrm{~h}$. Therefore, the possibility of leaching of 2 was excluded. The reactions catalysed by $3 a$ and $\mathbf{3 b}$ were conducted similarly. To our surprise, the yields gradually increased after the filtration and then reached $88 \%$ (3a) and $44 \%$ (3b) after stirring the filtrate for $19 \mathrm{~h}$. These results strongly suggested that the reaction catalysed by $\mathbf{3 a}$ or 3b was partly promoted by leaching Pt species, such as Pt nanoparticles. ${ }^{7 b, 22}$ Considering that 2 possesses many spare bipyridine units $(82 \%)$ that are densely arranged on the pore surface as determined above, we postulated that the free bipyridine would be helpful for suppression of leaching of $\mathrm{Pt}$ species from the pore surface.

\section{Recycle experiments of Pt catalyst immobilized on BPy-PMO}

Encouraged by the leaching experiments, we next examined the reusability of 1 and 2 (Fig. 4). The reaction of phenylacetylene with trimethoxysilane was performed for $15 \mathrm{~h}$ and the catalyst was recovered by simple filtration. It was found that the recovered 2 maintained good catalytic activity with slight loss of product yields for at least five times, indicating the good recyclability of 2 . Through the whole cycles, the ratio of two regioisomers $(\beta$-trans $/ \alpha)$ remained almost unchanged. Complex 1 were less active than $\mathbf{2}$ for each reaction cycle. This is probably because Pt atoms are partially immobilized on the silanol surface in $\mathbf{1}$. Interestingly, the catalytic activity of $\mathbf{1}$ was slightly 


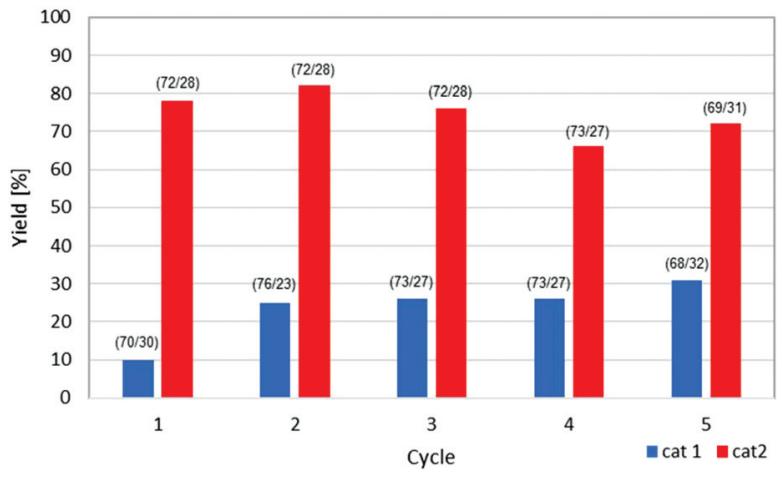

Fig. 4 Yields in recycle experiments on hydrosilylation of phenylacetylene and trimethoxysilane with $5 \mathrm{~mol} \%$ of 1 and 2 . The values in parentheses represent regioselectivity ( $\beta$-trans/ $\alpha$ ). Reaction conditions: Catalyst $(0.01 \mathrm{mmol} \mathrm{Pt})$, alkyne $(0.2 \mathrm{mmol})$, hydrosilane $(0.2 \mathrm{mmol})$ in benzene $(1 \mathrm{~mL})$ at $60{ }^{\circ} \mathrm{C}$ for $15 \mathrm{~h}$. Determined by ${ }^{1} \mathrm{H}$ NMR analysis with mesitylene $(0.2 \mathrm{mmol})$ as an internal standard.

improved after the second cycle. Since the hydrosilylated product reacts with silanol groups on the BPy-PMO surface, as noted above, it is likely that passivation of the surface proceeded during the reaction, and thus the catalytic activity could be somewhat improved after the reaction cycles.

To confirm the preservation of the mesoporous structure after the hydrosilylation, we measured XRD patterns and nitrogen adsorption/desorption isotherms of recovered PMO complex 2 after the fifth reaction. The XRD pattern for recovered 2 showed strong reflection at low angle of $1.80^{\circ}$ and four diffraction peaks at $7.60^{\circ}, 15.2^{\circ}, 22.9^{\circ}$, and $30.8^{\circ}$, suggesting the preservation of periodic mesoporous and crystal-like pore wall structures due to the robust covalent siloxane networks (Fig. S10 $\dagger$ ). The $S_{\mathrm{BET}}, V_{t \text {-plot, }}$ and $d_{\mathrm{DFT}}$ values of recovered 2 were $625 \mathrm{~m}^{2} \mathrm{~g}^{-1}, 0.39 \mathrm{~cm}^{3} \mathrm{~g}^{-1}, 3.8 \mathrm{~nm}$, respectively, clearly indicating preservation of the periodic mesoporous structure (Fig. S11†). The TEM images of recovered 2 suggested no formation of Pt particles, indicating that the Pt-bipyridine complex remained without aggregation even after the fifth reaction (Fig. S12†). ${ }^{23}$

\section{Experimental}

\section{Materials}

All chemicals were purchased from commercial suppliers (Sigma-Aldrich, Tokyo Chemical Industry Co., Ltd, and Wako Pure Chemical Industries, Ltd) and used without further purification. BPy-PMO and BPy-PMO end-capped with TMS groups (BPy-PMO-TMS) were prepared according to a previously reported procedure. ${ }^{8} \mathrm{BPy}_{4} \mathrm{C}_{4}$-FSM-16 and $\mathrm{BPy}-\mathrm{C}_{4}$-Silica gel were prepared according to a previously reported procedure with slight modification.

\section{Characterization of immobilized Pt complexes}

${ }^{29}$ Si dipolar decoupling (DD) MAS NMR measurement was performed at $79.49 \mathrm{MHz}$ at a sample spinning frequency of $4 \mathrm{kHz}$ using a Bruker Avance III 400 spectrometer with a $7 \mathrm{~mm}$ zirconia rotor. For the ${ }^{29} \mathrm{Si}$ MAS NMR measurements, the repetition delay was $60 \mathrm{~s}$, and the pulse width was $1.5 \mu \mathrm{s}$. Chemical shifts were referenced to hexamethylcyclotrisiloxane at $-9.68 \mathrm{ppm}$ as external standard for ${ }^{29} \mathrm{Si}$ NMR. X-ray diffraction (XRD) profiles were recorded by a Rigaku RINT-TTR diffractometer using $\mathrm{Cu}$ $\mathrm{K} \alpha$ radiation $(50 \mathrm{kV}, 300 \mathrm{~mA})$. Nitrogen adsorption/desorption isotherms were obtained using a Quantachrome Nova3000e sorptometer at liquid nitrogen temperature $\left(-196{ }^{\circ} \mathrm{C}\right)$. Brunauer-Emmett-Teller (BET) surface areas were calculated from the linear sections of BET plots $\left(P / P_{0}=0.1-0.2\right)$. Pore-size distributions were calculated using the DFT method (DFT kernel: $\mathrm{N}_{2}$ at $-196{ }^{\circ} \mathrm{C}$ on silica, cylindrical pores, nonlinear density functional theory (NLDFT) equilibrium model). Pore volumes were estimated using the $t$-plot method. Energy-dispersive X-ray spectrometry (EDX) was performed using a Hitachi S-3600N instrument. TEM observations were performed using a Jeol JEM-EX2000 operating at $5 \mathrm{kV}$ and $200 \mathrm{kV}$, respectively. UV-vis diffuse reflectance and absorption spectra were obtained using a Jasco V-670.

\section{Synthesis of PtMe ${ }_{2}(\mathrm{BPy}-\mathrm{PMO})(1)$ and $\mathrm{PtMe}_{2}$ (BPy-PMO-TMS) (2)}

A $50 \mathrm{~mL}$ Schlenk tube was equipped with a stir bar, ВРy-PMO

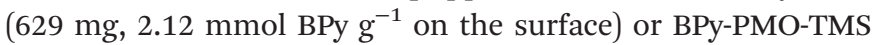

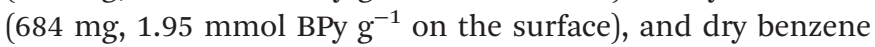
$(8 \mathrm{~mL})$. The mixture was stirred at $60{ }^{\circ} \mathrm{C}$. Then, a solution of $\left[\mathrm{PtMe}_{2}\left(\mu-\mathrm{SMe}_{2}\right)\right]_{2}(57 \mathrm{mg}, 0.1 \mathrm{mmol})$ in dry benzene $(20 \mathrm{~mL})$ was added dropwise at $60^{\circ} \mathrm{C}$. After stirring for ca. $5 \mathrm{~min}$ at the same temperature, the mixture was cooled to $6{ }^{\circ} \mathrm{C}$ and kept stirred for an additional $24 \mathrm{~h}$. The resulting suspension was filtered and then washed with dry benzene. The material was dried under reduced pressure to give $\mathrm{PtMe}_{2}(\mathrm{BPy}-\mathrm{PMO})(\mathbf{1})$ and $\mathrm{PtMe}_{2}$ (BPy-BPy-TMS) (2), respectively. The loading amounts of $\mathrm{Pt}$ in PMO complexes $\mathbf{1}$ and $\mathbf{2}$ were determined from the $\mathrm{Pt} / \mathrm{Si}$ ratios measured by energy-dispersive X-ray spectroscopy (EDX). The EDX analysis showed that the Pt/Si ratios were 0.041 and 0.037 for PMO complexes 1 and 2, respectively. Because of the $\mathrm{Si} / \mathrm{BPy}$ molar ratios are 2/1 for BPy-PMO and 10/3 for BPyPMO-TMS, ${ }^{8}$ the Pt/BPy molar ratios in $\mathbf{1}$ and $\mathbf{2}$ were calculated to be 0.082 and 0.12 , and thus corresponding to 0.26 and

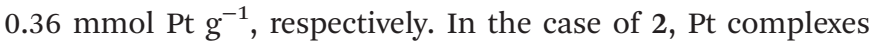
should be exclusively formed on the BPy ligands exposed on the surface layer of BPy-PMO pore wall which is composed of three layers of Si-BPy-Si unit. Therefore, the Pt/BPy $\mathrm{Burface}_{\text {are }}$ determined to be $18 \%$ for PMO complexes 2 and there are $82 \%$ of free bipyridine units on the pore surface.

\section{Synthesis of PtMe ${ }_{2}\left(\mathrm{BPy}^{-\mathrm{C}_{4}}-\mathrm{FSM}-16\right)$ (3a) and $\mathrm{PtMe}_{2}\left(\mathrm{BPy}^{-\mathrm{C}_{4}-}\right.$ Silica gel) (3b)}

A $50 \mathrm{~mL}$ Schlenk tube was equipped with a stir bar, $\mathrm{BPy}_{-} \mathrm{C}_{4}$ FSM-16 (500 mg, $0.38 \mathrm{mmol}$ BPy $\mathrm{g}^{-1}$ ) or BPy-C ${ }_{4}$-Silica gel (500 mg, $0.42 \mathrm{mmol}$ BPy $\mathrm{g}^{-1}$ ), and dry benzene $(5 \mathrm{~mL})$. The mixture was stirred at $60{ }^{\circ} \mathrm{C}$. Then, a solution of $\left[\mathrm{PtMe}_{2}\left(\mu-\mathrm{SMe}_{2}\right)\right]_{2}(73 \mathrm{mg}, 0.127 \mathrm{mmol})$ in dry benzene $(6 \mathrm{~mL})$ was added at $60{ }^{\circ} \mathrm{C}$. The reaction mixture was stirred at $6{ }^{\circ} \mathrm{C}$ 
for $20 \mathrm{~h}$. The resulting suspension was filtered and then washed with dry benzene. The material was dried under reduced pressure to give $\mathrm{PtMe}_{2}\left(\mathrm{BPy}-\mathrm{C}_{4}-\mathrm{FSM}-16\right)$ (3a) and $\mathrm{PtMe}_{2}\left(\mathrm{BPy}_{4}-\mathrm{C}_{4}\right.$-Silica gel) (3b), respectively.

\section{Typical procedure for hydrosilylation of phenylacetylene and trimethoxysilane}

A $20 \mathrm{~mL}$ Schlenk tube equipped with a stir bar was charged with phenylacetylene $(22 \mu \mathrm{L}, 0.2 \mathrm{mmol})$, mesitylene $(28 \mu \mathrm{L}$, $0.2 \mathrm{mmol}$ ), and $\mathrm{PtMe}_{2}$ (BPy-PMO-TMS) (2) (28 mg, $0.01 \mathrm{mmol}$ $\mathrm{Pt})$ in dry benzene $(1 \mathrm{~mL})$. Then, trimethoxysilane $(25 \mu \mathrm{L}$, $0.2 \mathrm{mmol}$ ) was added dropwise to the suspension. The reaction mixture was stirred for $15 \mathrm{~h}$ at $60{ }^{\circ} \mathrm{C}$. The heterogeneous catalyst was removed by passing through a membrane filter $(0.1 \mu \mathrm{m})$. The yield of the product was determined by ${ }^{1} \mathrm{H}$ NMR analysis with mesitylene as an internal standard. ${ }^{1} \mathrm{H}$ NMR spectra of the products, $\beta$-trans- and $\alpha$-(trimethoxysilyl)styrene, were reported in the literature. ${ }^{24}$

\section{Conclusions}

In this study, we prepared the Pt complex directly immobilized on BPy-PMO, and BPy-PMO-TMS as well as Pt complexes with other silica-based bipyridine ligands possessing functional linkages. The reaction of both BPy-PMO and BPy-PMO-TMS with $\left[\mathrm{PtMe}_{2}\left(\mu-\mathrm{SMe}_{2}\right)\right]_{2}$ provided the corresponding Pt complexes 1 and 2, respectively. Complex 1 exhibited moderate catalytic activity in the hydrosilylation of phenylacetylene with trimethoxysilane, probably due to the partial formation of undesired Pt complex coordinated with free silanol moieties. It is also to be mentioned that the reaction of silanol moieties with the hydrosilylatd product also lead to the decrease in the apparent production yield. In contrast, complex 2 with BPyPMO-TMS, which was end-capped with TMS groups on the surface silanol groups, effectively catalysed the hydrosilylation reaction. Hot filtration experiments excluded the occurrence of leaching of 2 during the reactions. In contrast, leaching of the grafted complexes $\mathbf{3 a}$ and $\mathbf{3 b}$ was observed. We postulated that the utility of free bipyridine units in 2, which are densely arranged on the pore surface, could suppress the leaching behavior. Complex 2 showed good reusability without the loss of the product yield for at least five reuse cycles in hydrosilylation. Overall, the superior utility of BPy-PMO-TMS as a solid-support ligand for Pt-catalysed hydrosilylation was demonstrated.

\section{Conflicts of interest}

There are no conflicts to declare.

\section{Acknowledgements}

This work was supported by the "Development of Innovative Catalytic Processes for Organosilicon Functional Materials" project (Project Leader: K. Sato) from the New Energy and
Industrial Technology Development Organization (NEDO). The authors thank Dr Yasutomo Goto and Dr Masamichi Ikai (Toyota Central R\&D Laboratories, Inc.) for TEM observations and SEM-EDX analysis.

\section{Notes and references}

1 (a) L. N. Lewis, J. Stein, Y. Gao, R. E. Colborn and G. Hutchins, Platinum Met. Chem., 1997, 41, 66-75; (b) Y. Nakajima and S. Shimada, RSC Adv., 2015, 5, 2060320616; (c) D. Troegel and J. Stohrer, Coord. Chem. Rev., 2011, 255, 1440-1459; (d) B. G. Marciniec, Coord. Chem. Rev., 2005, 249, 2374-2390; (e) D. Xiaoyong and H. Zheng, ACS Catal., 2017, 7, 1227-1243.

2 (a) J. L. Speier, J. A. Webster and G. H. Barnes, J. Am. Chem. Soc., 1957, 79, 974-979; (b) J. L. Speier, Adv. Organomet. Chem., 1979, 17, 407-447.

3 B. D. Karstedt, General Electric Company, US3775452A, 1973.

4 A. J. Holwell, Platinum Met. Rev., 2008, 52, 243-266.

5 (a) M. Pagliaro, R. Ciriminna, V. Pandarus and F. Béland, Eur. J. Org. Chem., 2013, 6227-6235; (b) Y. Bai, J. Peng, J. Li, G. Lai and X. Li, Prog. Chem., 2011, 23, 2466-2477; (c) H. Bai, Ind. Eng. Chem. Res., 2014, 53, 1588-1597.

6 (a) L. Wang and Y. Jiang, J. Organomet. Chem., 1983, 251, 39-44; (b) C.-Y. Hu, X.-M. Han and Y.-Y. Jiang, J. Mol. Catal., 1986, 35, 329-333; (c) W. R. Cullen and N. F. Han, J. Organomet. Chem., 1987, 333, 269-280; (d) R. Drake, R. Dunn, D. C. Sherrington and S. J. Thomson, Chem. Commun., 2000, 1931-1932; (e) Z. M. Michalska, Ł. Rogalskia, K. Rózga-Wijas, J. Chojnowski, W. Fortuniak and M. Ścibiorek, J. Mol. Catal. A: Chem., 2004, 208, 187194; (f) J. Li, C. Yang, L. Zhang and T. Ma, J. Organomet. Chem., 2011, 696, 1845-1849.

7 (a) Q. J. Miao, Z. Fang and G. P. Cai, Catal. Commun., 2003, 4, 637-639; (b) T. Galeandro-Diamant, R. Sayah, M. Zanota, S. Marrot, L. Veyre, C. Thieuleux and V. Meille, Chem. Commun., 2017, 53, 2962-2965.

8 M. Waki, Y. Maegawa, K. Hara, Y. Goto, S. Shirai, Y. Yamada, N. Mizoshita, T. Tani, W.-J. Chun, S. Muratsugu, M. Tada, A. Fukuoka and S. Inagaki, J. Am. Chem. Soc., 2014, 136, 4003-4011.

9 Y. Maegawa and S. Inagaki, Dalton Trans., 2015, 44, 1300713016.

10 X. Liu, Y. Maegawa, Y. Goto, K. Hara and S. Inagaki, Angew. Chem., Int. Ed., 2016, 55, 7943-7947.

11 N. Ishito, H. Kobayashi, K. Nakajima, Y. Maegawa, S. Inagaki, K. Hara and A. Fukuoka, Chem. - Eur. J., 2015, 21, 15564-15569.

12 Y. Kuramochi, M. Sekine, K. Kitamura, Y. Maegawa, Y. Goto, S. Shirai, S. Inagaki and H. Ishida, Chem. - Eur. J., 2017, 43, 10301-10309.

13 M. Waki, K.-I. Yamanaka, S. Shirai, Y. Maegawa, Y. Goto, Y. Yamada and S. Inagaki, Chem. - Eur. J., 2018, 24, 38463853. 
14 N. Ishito, K. Nakajima, Y. Maegawa, S. Inagaki and A. Fukuoka, Catal. Today, 2017, 298, 258-262.

15 S. Ishikawa, Y. Maegawa, M. Waki and S. Inagaki, ACS Catal., 2018, 8, 4160-4169.

16 K. Matsui, Y. Maegawa, M. Waki, S. Inagaki and Y. Yamamoto, Catal. Sci. Technol., 2018, 8, 534-539.

17 M. Yoshida, K. Saito, H. Matsukawa, S. Yanagida, M. Ebina, Y. Maegawa, S. Inagaki, A. Kobayashi and M. Kato, J. Photochem. Photobiol., A, 2018, 358, 334-344.

18 (a) J. D. Scott and R. J. Puddephatt, Organometallics, 1983, 2, 1643-1648; (b) P. K. Monaghan and R. J. Puddephatt, Organometallics, 1984, 3, 444-449; (c) D. Minniti, G. Alibrandi, M. L. Tode and R. Romeo, Inorg. Chem., 1987, 26, 3956-3958; (d) M. Rehdi, Z. Fakhroeian and R. J. Puddephatt, J. Organomet. Chem., 1991, 406, 261-267.

19 A. Klein, J. van Slageren and S. Záliš, Eur. J. Inorg. Chem., 2003, 1917-1928.

20 A review, see: (a) B. M. Trost and Z. T. Ball, Synthesis, 2005, 853-887. Pioneering examples of Pt-catalysed hydrosilylation of alkynes, see: (b) L. N. Lewis, K. G. SyG. L. Bryant Jr. and P. E. Donahue, Organometallics, 1991, 10, 3750-3759; (c) M. G. Voronkov, V. B. Pukhnarevich, I. I. Tsykhanskaya, N. I. Ushakova, Y. L. Gaft and I. A. Zakharova, Inorg. Chim. Acta, 1983, 68, 103-105; (d) M. Green, J. L. Spencer, F. G. A. Stone and C. A. Tsipis, J. Chem. Soc., Dalton Trans., 1977, 1525-1529; (e) C. A. Tsipis, J. Organomet. Chem., 1980, 187, 427-446.

21 H. Noda, K. Motokura, A. Miyaji and T. Baba, Angew. Chem., Int. Ed., 2012, 51, 8017-8020.
22 (a) L. N. Lewis, J. Stein, Y. Gao, R. E. Colborn and G. Hutchins, Platinum Met. Rev., 1997, 41, 66-75; (b) R. Ciriminna, V. Pandarus, G. Gingras, F. Béland and M. Pagliaro, ACS Sustainable Chem. Eng., 2013, 1, 249-253.

23 Examples of single atom catalysts (SACs) based on Pt, see: (a) X. Cui, K. Junge, X. Dai, C. Kreyenschulte, M. M. Pohl, S. Wohlrab, F. Shi, A. Brückner and M. Beller, ACS Cent. Sci., 2017, 3, 580-585; (b) J. L. Liu, F. R. Lucci, M. Yang;, S. Lee, M. D. Marcinkowski, A. J. Therrien, C. T. Williams, E. C. Sykes and M. Flytzani-Stephanopoulos, J. Am. Chem. Soc., 2016, 138, 6396-6399; (c) F. Dvořák, M. F. Camellone, A. Tovt, N.-D. Tran, F. R. Negreiros, M. Vorokhta, T. Skála, I. Matolínová, J. Mysliveček, V. Matolín and S. Fabris, Nat. Commun., 2016, 7, 10801-10807; (d) B. Qiao, A. Wang, X. Yang, L. F. Allard, Z. Jiang, Y. Cui, J. Liu, J. Li and T. Zhang, Nat. Chem., 2011, 3, 634-641; (e) H. Wei, X. Liu, A. Wang, L. Zhang, B. Qiao, X. Yang, Y. Huang, S. Miao, J. Liu and T. Zhang, Nat. Commun., 2014, 5, 5634-5640; (f) S. Yang, J. Kim, Y. J. Tak, A. Soon and H. Lee, Angew. Chem., Int. Ed., 2016, 55, 2058-2062; $(g)$ B. Zhang, H. Asakura, J. Zhang, J. Zhang, S. De and N. Yan, Angew. Chem., Int. Ed., 2016, 55, 8319-8323; (h) M. Moses-DeBusk, M. Yoon, L. F. Allard, D. R. Mullins, Z. Wu, X. Yang, G. Veith, G. M. Stocks and C. K. Narula, J. Am. Chem. Soc., 2013, 135, 12634-12645; (i) J. Wang, X. Zhao, N. Lei, L. Li, L. Zhang, S. Xu, S. Miao, X. Pan, A. Wang and T. Zhang, ChemSusChem, 2016, 9, 784-790.

24 C.-H. Jun and R. H. Crabtree, J. Organomet. Chem., 1993, 447, 177-187. 